\title{
Uma corpo-política \\ do conhecimento feminino: questionar pelos sentidos, pelos corpos e pelo sul
}

\author{
A political body of female knowledge: questioning the senses, bodies and \\ the south
}

\section{Una cuerpo política del conocimiento femenino: cuestionar los sentidos, los cuerpos y el sur}

\author{
Nathalia Flores Soares ${ }^{1}$ \\ Edgar Cézar Nolasco ${ }^{2}$
}

\begin{abstract}
Resumo
Este trabalho vai em busca de um diálogo critico entre a escrita autobiográfica da professora, intelectual e escritora Heloísa Buarque de Hollanda e as relações imbricadas nos contextos culturais, sociais e marginais presentes nas regiões (ex)cêntricas do país, na tentativa de reatualizar problemáticas já delineadas no passado, o enfoque se voltara para as teorizações feministas delineadas pela professora ao decorrer de seu projeto intelectual. Pretende-se aqui mostrar como a escrita do eu revela tensões ideológicas, epistêmicas e críticas na vida de quem se propõe a escrever autobiografias, sendo assim, o objeto norteador será a obra Escolhas (2009). Em síntese, a análise se voltará para a condição das mulheres latinas americanas, precisamente no cenário brasileiro contemporâneo, com enfoque na crescente onda de manifestações feministas, na rua e na academia.
\end{abstract}

Palvras-chave: Feminismo; Heloísa Buarque de Hollanda; Pensamento Fronteiriço.

\begin{abstract}
This work seeks a critical dialogue between the autobiographical writing of the teacher, intellectual and writer Heloísa Buarque de Hollanda and the intertwined relationships in the cultural, social and marginal contexts present in the (ex) centric regions of the country, in an attempt to update problems already outlined in the past, the focus had turned to the feminist theorizations outlined by the teacher during her intellectual project. It is intended here to show how the writing of the self reveals ideological, epistemic and critical tensions in the life of those who intend to write autobiographies, therefore, the guiding object will be the work Escolhas (2009). In summary, the analysis will turn to the condition of Latin American women, precisely in the contemporary Brazilian scenario, with a focus on the growing wave of feminist manifestations, in the street and in the academy.
\end{abstract}

\footnotetext{
${ }^{1}$ Mestranda em Estudos de Linguagens com o projeto "Heloisa Buarque de Hollanda: uma leitura críticobiográfica fronteiriça" pela Universidade Federal do Mato Grosso do Sul. Graduada em Letras Licenciatura Habilitação Português/Espanhol e suas Literaturas pela Universidade Federal do Mato Grosso do Sul. Membro do Núcleo de Estudos Culturais Comparados (NECC) Tem experiência na área de Letras, com ênfase em Teoria Literária, Estudos Culturais, Crítica Biográfica, Literatura Comparada, Literatura Brasileira e Estudos Descoloniais. E-mail: nathalia.f.soares@hotmail.com

${ }^{2}$ Professor titular da UNIVERSIDADE FEDERAL DE MATO GROSSO DO SUL. Possui mestrado em Teoria da Literatura (UFMG), doutorado em Literatura Comparada (UFMG), com pós-doutorado em Cultura (PACCUFRJ). Ministra as disciplinas Teoria da Literatura e Literatura Comparada na Graduação em Letras e Literatura Comparada e Teorias sem disciplina na Pós-Graduação Estudos de Linguagens. É fundador e coordenador do NECC: NÚCLEO DE ESTUDOS CULTURAIS COMPARADOS (desde 2009), e editor-presidente dos periódicos do grupo CADERNOS DE ESTUDOS CULTURAIS (desde 2009). Além de estudioso da obra de Clarice Lispector, tem pesquisado e orientando projetos acerca dos Estudos descoloniais/fronteiriços. E-mail: ecnolasco@uol.com.br
} 
Key words: Feminism; Heloísa Buarque de Hollanda; Frontierthinking.

\section{Resumen}

Este trabajo busca un diálogo crítico entre la escritura autobiográfica de la maestra, intelectual y escritora Heloísa Buarque de Hollanda y las relaciones entremezcladas en los contextos culturales, sociales y marginales presentes en las regiones (ex) céntricas del país, en un intento de actualización. Problemas ya descritos en el pasado, el enfoque se había centrado en las teorías feministas esbozadas por la maestra durante su proyecto intelectual. Aquí se pretende mostrar cómo la escritura del yo revela tensiones ideológicas, epistémicas y críticas en la vida de quienes proponen escribir autobiografías, por lo tanto, el objeto rector será el trabajo de Escolhas (2009). En resumen, el análisis se centrará en la condición de las mujeres latinoamericanas, precisamente en el escenario brasileño contemporáneo, centrándose en la creciente ola de manifestaciones feministas, en la calle y en la academia.

Palabrasclave: feminismo; Heloísa Buarque de Hollanda; El pensamiento fronterizo.

O pensamento de fronteira não é um fundamentalismo antimoderno. É uma resposta transmodernadescolonial do subalterno perante a modernidade eurocêntrica. (GROSFOGUEL.2009, p.407.)

O projecto de uma epistemologia do Sul é indissociável de um contexto histórico em que emergem com particular visibilidade e vigor novos actores históricos no Sul global, sujeitos colectivos de outras formas de saber e de conhecimento que, a partir do cânone epistemológico ocidental, foram ignorados, silenciados, marginalizados, desqualificados ou simplesmente eliminados, vítimas de epistemicídios tantas vezes perpetrados em nome da Razão, das Luzes e do Progresso. (NUNES. 2009, p.233)

Ahora entre los dioses ajenos con armas de magia me encontro yo. (ANZALDÚA. 1987, p.52.)

A densidade da História não determina nenhum de meus atos.Eu sou meu próprio fundamento.É superando o dado histórico, instrumental, que introduzo o ciclo de minha liberdade. (FANON. 2008, p.190).

\section{Introdução: Sensibilidades femininas}

A leitura implica sempre em escolhas, nossas escolhas e de Heloisa Buarque de Hollanda são compartilhadas, a canibalizamos e a temos como nossa aliada, por compreender que o projeto intelectual da autora funciona como complementador, assim como as leituras de Heloisa, os autores que aqui elencamos para essa conversa epistêmica de uma maneira ou outra compõem nosso imaginário teórico, social e político.

Sendo assim, as epigrafes apostas ao seu modo ilustram nosso argumento em favor da opção descolonial como uma opção de vida, que vai na contra mão das epistemologias cognitivas imperiais e se volta pra os estudos subalternos como uma respostas crítica aos fundamentalismos universais (GROSFOGUEL, 2009, p.385), iremos argumentar em favor dos estudos feministas, como uma crítica epistemológica ao mundo patriarcal-colonial- 
moderno, para tanto, utilizaremos nossas experiências que se acostam na fronteira de Mato Grosso do Sul, essa ferida aberta de um país onde tudo acontece nos grandes centros (Rio-São Paulo), bem como, a atuação de Heloisa enquanto feminista pautada em uma opção descolonial.

Na esteira dessa afirmação, pensamos na atuação de nossa aliada enquanto feminista como uma desobediência à norma falocêntrica que grassa no mundo, visto que a intelectual sofreu várias perseguições no meio acadêmico, por ser a única mulher a concorrer ao aclamado concurso da Escola de Comunicações da UFRJ, desse modo, o feminismo se intensifica e se torna imprescindível para sua atuação profissional e pessoal. Evocamos as teorizações de Nunes quando o autor disserta sobre as contribuições do feminismo para a epistemologia do sul, compreendendo a crítica feminista como "um exercício de tradução que poderá ajudar a identificar as preocupações comuns, mas também as concepções divergentes que movem os dois campos em diálogo".(NUNES, 2009, p.237)

$\mathrm{O}$ fato é que o feminismo pode ser entendido como uma primeira mudança perante o mundo patriarcal, em livro recente lançado, Heloisa disserta sobre a situação do feminismo dito descolonial, bem como a importância de sua urgência:

\footnotetext{
como construir um feminismo sem levar em conta as epistemologias originárias? Sem absorver as gramáticas das lutas e dos levantes emancipatórios que acompanham nossas histórias? Como podemos reconsiderar as fontes e conceitos do feminismo Ocidental? Uma nova história, novas solidariedades, novos territórios epistêmicos impõem urgência em ser sonhados (HOLLANDA, 2020, s/p).
}

Entendemos as palavras de Hollanda como uma perspectiva epistêmica que está alocada nas sensibilidades locais e nas histórias originárias das mulheres latino-americanas, para tanto, somente um pensamento de fronteira que se paute em um campo epistêmico mais abrangente dará conta de sublinhar as distintas subjetividades dos corpos femininos. Nas palavras do autor Ramon Grosfoguel: "uma perspectiva epistémica descolonial exige um cânone de pensamento mais amplo do que o cânone ocidental” (GROSFOGUEL, 2009, p.385).

A autora busca ampliar o cânone feminista ocidental por compreender que as subjetividades suscitadas pelo feminismo clássico foram responsáveis por excluir as histórias originárias dos corpos femininos alocados na exterioridade do pensamento moderno. $\mathrm{O}$ fato é que existe uma matriz de poder colonial que comanda e hierarquiza as histórias locais e os saberes, desse modo, as sensibilidades das mulheres latino americanas são sempre da ordem do fora. 


\section{Desenvolvimento: A opção descolonial como re-existência}

Elegemos a opção descolonial e o pensamento de fronteira como forma de compreender as subjetividades femininas compartilhadas por intelectuais mulheres do dito terceiro mundo, nossa condição fronteiriça nos conecta com os autores complementadores de forma simbiótica, formamos duetos que originam o que aqui estou chamando de feminismo decolonial, para Grosfoguel: "Esta questão não tem a ver apenas com valores sociais na produção de conhecimento nem com o facto de o nosso conhecimento ser sempre parcial. $\mathrm{O}$ essencial aqui é o locus da enunciação, ou seja, o lugar geopolítico e corpo-político do sujeito que fala" (GROSFOGUEL, 2009, p.386). Nos amparamos nas preposições de Grosfoguel como forma de contribuir para nossa argumentação, haja vista que um dos mecanismos da matriz de poder colonial é a exclusão do lócus de enunciação, do corpo e da geopolítica do sujeito que fala, o que estamos aqui defendendo é o direito de se pensar corpo-politicamente e geopoliticamente na condição de mulheres que sofrem e habitama fronteira em que sobrevivem, a mesma que nós pesquisadores habitamos.

Há um mito ocidental, patriarcal, moderno e colonial que paira em todas as relações que versam no mundo, sejam elas politicas culturais e sociais, é por meio da sistematização e da organização de vários mundos em um só que a matriz colonial de poder vê a possibilidade de continuar atuando no mundo e intermediando as relações. Esse mito está presente nas relações ao que cerne a sexualidade, homossexuais e mulheres têm seus corpos constantemente desconsiderados em prol de uma hierarquização sexual, nessa o individuo masculino-branco-europeu vem em primeiro lugar sobre os demais sujeitos. Exposto isso, nos ancoramos na opção descolonial uma vez mais como nas teorizações de Grosfoguel: "repensar o mundo colonial/moderno a partir da diferença colonial altera importantes pressupostos dos nossos paradigmas" (GROSFOGUEL, 2009, p.397).

Mudar o paradigma, ou como em espanhol cambiar el mundo, não é uma tarefa fácil, contudo, é só a partir da diferença colonial que nos contempla enquanto pesquisadores da fronteira sul de Mato Grosso do Sul, nosso lugar de luta na busca de desmistificar o império cognitivo excludente. Estudar e pesquisar acerca das teorizações de Heloisa Buarque de Hollanda é aprender o mundo que as mulheres experenciam a partir da diferença, e é desse modo única e exclusivamente que conseguimos melhor compreender a luta que as mulheres travam e sangram na tentativa de crescer em um mundo cruel e sanguinolento, compartilhamos do mesmo ideal feminista de Heloisa quando assume que: 
Um caminho possível em busca de uma perspectiva decolonial brasileira seria uma análise radical da especificidade da questão de nossa mestiçagem, priorizando suas implicações em termos dos processos constitutivos das desigualdades sociais.(HOLLANDA, 2020, s/p)

$\mathrm{Na}$ esteira das preposições da autora, concordamos que a descolonialidade se constrói enquanto nosso caminho possível para interpelar o projeto moderno, priorizar as histórias locais, a mestiçagem e a situação de mulheres que habitam as fronteiras desse país colossal, desde o momento em que compreendemos a opção descolonial como uma teorização mais abrangente entre os vários mundos e diferenças que existem em nossa sociedade, pudemos melhor compreender o lugar em que vivemos, bem como nossa pesquisa. Estamos distantes fisicamente, mas podemos compartilhar vivências teorizações e ir além dos conceitos epistêmico moderno de conhecimento que existe nas universidades. Acerca dessas argumentações, trazemos à baila as teorizações de Grosfoguel quando afirma que:

Estes conceitos precisam ser descolonizados e tal só pode ser conseguido por meio de uma epistemologia descolonial que assuma abertamente uma geopolítica e uma corpo-política do conhecimento descoloniais como pontos de partida para uma crítica radical (GROSFOGUEL, 2009, p.389)

Pautamos-nos nas teorizações de Grosfoguel por pensar em um mundo onde o conceito de mulher possa ser descolonizado, o indivíduo feminino foi durante muitos anos estigmatizado pela matriz de poder colonial como inferior, somente trabalhava com serviços domésticos, inferior intelectualmente e fisicamente, não fazia parte das decisões da sociedade e não podia tomar partido político, o que vemos hoje é uma virada radical na concepção e no conceito de "mulher", como nas palavras de Anzaldúa "agora todas las partes de nosotras valén" (ANZALDÚA, 1980, p.147)

$\mathrm{O}$ fato é que o pensamento fronteiriço funciona como uma resposta às epistemologias imperiais (GROSFOGUEL, 2009, p.407), uma resposta que emerge do outro lado da linha, do lado mestiço, subalterno, aqui estou argumentando a favor do pensamento fronteiriço como uma reação ao machismo colonial, bem como estamos defendendo o feminismo como uma mudança de paradigma radical das relações hierárquicas que existem na sociedade, para tanto utilizamos como aporte nossa pesquisa para que essa teorização se consolide como uma mudança não só da ordem intelectual mas da ordem da vida.

Dessa forma, o pensamento fronteiriço demanda uma epistemologia outra, optamos pelo conceito de Santos acerca das epistemologias do Sul como um caminho possível para dissuadir as barreiras impostar pelo saber imperial cognitivo, na esteira desses argumentos, João Arriscado Nunes afirma que as epistemologias do sul funcionam como: "um recurso para o resgate da epistemologia, para a sua reconstrução radical como epistemologia do Sul e 
como parte da emergência de um pensamento pós-abissal” (NUNES, 2009, p.230), a emergência do pensamento pós-abissal, bem como do feminismo descolonial está pautada no resgate das epistemologias dos povos originários e na criação de projetos intelectuais abrangentes e dinâmicos, que coexistam radicalmente, "para abordar um mundo que é mais do que o mundo ocidental e uma compreensão do mundo que não se esgota"(NUNES, 2009, p.231).

A epistemologia que Nunes pretende resgatar é a do Sul, na esteira das argumentações de Santos, o autor versa sobre a possibilidade de um diálogo entre as epistemologias modernas e as do Sul, tendo em mente que a opção descolonial não repete a velha doxa moderna e não tem pretensão alguma de se impor como conhecimento universal. Pensando no projeto de Heloisa, o feminismo clássico (pensado na Europa e Estados Unidos) se insere como universal abstrato por não contemplar as sensibilidades distintas de mulheres e os vários loci de enunciação, a descolonialidade surge como a possibilidade de representação de vidas engastadas na fronteira e de projetos intelectuais que estão longe demais das capitais,como em nosso caso, a rubrica feminismo descolonial como nas palavras de Heloisa é uma das formas de fazer com que:" o valor politico da memória e da arte ganha a cena nas periferias" (HOLLANDA, 2020, s/p)

Não nos desvencilhando de todos os textos aqui citados, evocamos o espectro de Walter Mignolo em posfácio intitulado "Después de America $<$ Latina $>$ una véz más" por compreender a necessidade de se possuir um respaldo teórico diversificado para que a teorização a qual proponho se consolide como um campo intermediado pelas várias vozes que se entrecruzam no processo de escrita. No seguinte texto Mignolo disserta sobre a ideia de América Latina e sobre o processo de desmontagem colonial ao qual continuamos lutando, o autor afirma que o pensamento descolonial não pensa mais a partir da Europa, mas sim com base nas histórias locais dos lugares os quais os povos habita, clamando por uma diferença de ordem epistemológica no processo de assimilação do conhecimento. Mignolo assevera: "una diferencia epistémica que sostiene sus reclamaciones de intervención política y económica;y, sobre todo, conquistar la dignidad por sus proprias manos.” (MIGNOLO, 2007, p.204)

$\mathrm{Na}$ esteira dos pensamentos de Mignolo, utilizamos o projeto intelectual de Heloisa acerca do feminismo descolonial para estabelecer uma discussão de ordem epistemológica com os vários autores aqui elencados, na tentativa de situar os corpos femininos para além do império cognitivo europeu e norte-americano, desse modo, a diferença epistêmica é imprescindível para que mulheres possam sustentar suas lutas cotidianas e possam ter a dignidade de seus corpos levada em consideração. Não há mais espaço para violência, para o 
patriarcado uma vez que mulheres se levantem contra toda essa matriz colonial em busca de uma politica que preze por vidas, "uma consciência outra está em formação - uma nova consciência mestiza, uma conciencia de mujer. Uma consciência das fronteiras" (ANZALDÚA, 1980, p.133)

\section{Conclusão}

O que as mulheres têm vivido desde a formação da sociedade é como uma luta de fronteiras, uma luta de carne/corpos, lugares espaciais, uma luta pelo direito de ser tratada com dignidade, recuso $a$ "generosa assimilação" (MIGNOLO, 2007, p.205) que foi imposta na pele e feriu suas dignidades pelo fato de ter nascido mulher, desse modo, nosso trabalho enquanto pesquisadores é dissuadir as barreiras que nos impedem de ressaltar nossas sensibilidades. Dito isso, decidimos agir ao em vez de apenas reagir, e agir demanda posicionar-nos na outra margem do rio, do outro lado da linha, em direção de "aprender a desaprender y de aprender a ser" (MIGNOLO, 2007, p.205), aprender o valor dos corpos femininos, o valor de Heloisa e todos nós que lutamos incessantemente pela conquista de nossos direitos, desprender das amarras patriarcais modernas e trilhar um caminho rumo a uma nova consciência.

Consciência essa que se projeta para o futuro, acerca disso Heloisa pondera: "Ficou clara a forma de articulação das mulheres pela memória, através da qual se conectam, se identificam e produzem uma proposta de consciência diferencial que toma o lugar da consciência identitária." (HOLLANDA, 2020, s/p), a rearticulação de mulheres é necessária para que as barreiras da desigualdade sejam dissuadidas, um pensamento descolonial que leve em conta as memórias e histórias locais de corpos femininos e se paute na diferença é o melhor meio de consolidar a proposta de nossas teorizações, Walter Mignolo afirma que a opção descolonial é uma visão do futuro que conecta projetos políticos e se origina de várias nações (MIGNOLO, 2007, p.213).

Apesar de toda a discussão de nível teórico que evoquei até aqui, não posso deixar de lado minhas sensibilidades, recordo de minhas primeiras leituras acerca de Heloisa Buarque de Hollanda, quando me deparei com a escrita de minha aliada em sua obra Escolhas (2009) ali eu viria a saber que a escrita autobiográfica suscita diferentes questões para homens e mulheres, questões essas que me tirariam de meu lugar de conforto e me fariam ressignificar as várias esferas de minha vida pessoal, inclusive o lugar onde habito. Assim como nas teorizações de Anzaldúa, entendo que uma fronteira é mais que uma demarcação politica de 
terra, nossas subjetividades estão dissuadidas na fronteira, enquanto sangramos na fronteira e a tensão se apodera de nós e de nosso corpo na busca de direitos iguais. Nas palavras de Anzaldúa:

\footnotetext{
a frontera é una herida abierta donde el Tercer mundo se araña contra el primero y sangra. Y antes de que se forme costra, vuelve la hemorragia, la savia vital de dos mundos que se funde para formar un tercer país, una cultura de frontera.(ANAZALDÚA, 1980, p.42)
}

Assim também são os corpos femininos, feridas abertas por um projeto falocêntrico, cruel e violento, sangram na tentativa de consolidar sua luta, é através da mudança de paradigma por parte de corpos femininos que se cria uma força vital, o fazer comunal das mulheres em re-existência é capaz de mudar o mundo e desvencilhar-nos das tradições modernas em busca da consolidação de nosso sonho.

As fronteiras possuem desenhos que definem os lugares seguros e os ilegais, se constroem enquanto linhas divisórias entre o nós, no caso das mulheres entre elas e os homens, há um abismo entre essas fronteiras, como uma trincheira que somente pode ser atravessada por meio de uma ponte epistêmica que se respalde na diferença, nos movendo para o fora das formações cristalizadas do projeto imperial, as mulheres em situação fronteriza são "un amasiamento, sou um ato de juntar e unir que não apenas produz uma criatura tanto da luz como da escuridão, mas também uma criatura que questiona as definições de luz e escuro e lhes dá novos significados.” (ANAZALDÚA, 1980, p.138) .

Nossa luta e a de Heloisa sempre foram lutas interiores, a ingenuidade não nos é mais útil para mudar os panoramas que versam no mundo, compreendo nossa existência através do combate em um processo de escuta atenta de todas as sensibilidades femininas, visando o futuro, como outrora dissertou Fanon, "o passado não nos pode guiar na atualidade" (FANON, 2008, p.186) esse trabalho corpo-política-fronteiriço vai em direção ao futuro, ainda na esteira das preposições de Fanon, não podemos ser prisioneiros da história, história essa de aniquilação das mulheres, do sujeitos fronteiriços, somos nosso fundamento, "eu sou o meu próprio fundamento é superando o dado histórico, instrumental, que introduzo o ciclo de minha liberdade”. (FANON, 2008, p.190) nossas escolhas vão em direção à liberdade e à autonomia de nossos loci de enunciação e de nossos corpos.

\section{Referências}

ANZALDÚA, Gloria. Borderlands/la frontera: la nueva mestiza. Trad. de Carmen Valle. Madrid: Capitán Ewing Libros, S. L. 
BOAVENTURA, S. S Meneses, M.P Epistemologias do Sul. Coimbra. Almeidina, 2009.

FANON. Pele negra, máscaras brancas. Salvador: EDUFBA, 2008.

HOLLANDA, Heloisa Buarque de. Escolhas: uma autobiografia intelectual. Rio de Janeiro: Editora Língua Geral, 2009.

HOLLANDA, Heloisa Buarque de. Pensamento feminista hoje: perpectivas decoloniais. Rio de Janeiro, Bazar do tempo, 2020.

MIGNOLO. La idea de América Latina. Barcelona: Editorial Gedisa, 2007. 